\title{
Solutions Manual
}

\author{
for \\ Introduction to Internal Combustion \\ Engines
}

\author{
Richard Stone \\ University of Oxford \\ Department of Engineering Science
}

(0) Richard Stone 1999

Direct Line (01865) 273120 FAX 273905

Email richard.stone@eng.ox.ac.uk 
(C) Richard Stone 1999

All rights reserved.

Copying of the content of this manual is permitted only for sole or classroom use. Otherwise, the content may not be copied, transmitted, adapted or changed in any way for any other reason without prior written permission from the publisher.

Any person who does any unauthorised act in relation to this publication may be liable to criminal prosecution and civil claims for damages.

First published 1999 by

MACMILLAN PRESS LTD

Houndmills, Basingstoke, Hampshire RG21 6XS

and London

Companies and representatives

throughout the world

ISBN 978-0-333-79307-7

DOI 10.1007/978-1-349-15079-3

A catalogue record for this book is available from the British Library.

This book is printed on paper suitable for recycling and made from fully managed and sustained forest sources.

$\begin{array}{llllllllll}10 & 9 & 8 & 7 & 6 & 5 & 4 & 3 & 2 & 1\end{array}$

$\begin{array}{llllllllll}08 & 07 & 06 & 05 & 04 & 03 & 02 & 01 & 00 & 99\end{array}$ 


\section{PREFACE}

The popularity of Introduction to Internal Combustion Engines during the last ten years or so, has prompted me to prepare this set of worked solutions for the $3^{\text {rd }}$ Edition. I have used many of the questions as exam questions, so during the marking of the scripts, I hope that I will have removed any errors. None the less, readers may encounter some errors, in which case I would be very grateful to hear about them.

So as to make this manual self-contained, I have included the questions, and for clarity these have been written in bold type. The questions in the 2 nd Edition have been denoted by a superscript asterisk ("). At the end of many questions I have added a Discussion. This contains material that is strictly speaking beyond the scope of the question, but is intended to be useful supplementary information. This manual provides a useful means of adding supplementary material, as occasionally some of the discussion material, (especially in the discussiontype questions) is not in the book.

All Figure numbers and Equation numbers refer to the $3^{\text {rd }}$ Edition of the book, and to avoid any confusion, letters have been used in this Manual to define equations. The nomenclature and abbreviations are consistent with the book, with the exception of time derivatives for which it has not been possible to include the 'dot'. This means, for example, that work and power are both denoted by $W$, but it should be clear from the comments, units and context what is being used. Bold italics are used on occasion to indicate entries in the index for topics that are treated in the book, and do not form a core part of the solution. The final answers to each part of a question are shown in bold font.

In order to make this manual self contained, the Appendix contains thermodynamic tables for combustion calculations; this should also ensure consistency in the answers if these tables are made available to students. The tables contain equilibrium constants, and molar thermodynamic property data (internal energy, enthalpy, Gibbs Energy, and Entropy) for the species to be found in the reactants and products. The datum for enthalpy adopted here, is a datum of zero enthalpy for elements when they are in their standard state at a temperature of $25^{\circ} \mathrm{C}$. The enthalpy of any molecule at $25^{\circ} \mathrm{C}$ will thus correspond to its enthalpy of formation, $\Delta H_{\mathrm{f}}^{\circ}$. This choice of datum (although not used to my knowledge in any other tables) will be seen to facilitate energy balances in combustion. Unlike tables that use an identical datum for reactant and product species, there is no need to include enthalpies or internal energies of reaction. Since the first publication of Introduction to Internal Combustion Engines the preferred practice for denoting molar quantities is to use a lower case letter ( to emphasise that it is a specific quantity) with a tilde above, for example n. However, for consistency with the book (and in common with many other publications) molar quantities will be denoted here by upper case letters. This requires the reader to decide whether the symbol refers to a molar specific quantity, or a property value of the complete system.

Some of the combustion problems have been generated using the equilibrium solving package STANJAN, developed by Prof W C Reynolds of Stanford University. 